\title{
Announcement of the Next Meeting of the EMS Council Prague, June 23 and 24, 2018
}

The EMS Council meets every second year. The next meeting will be held in Prague, June 23 and 24, 2018 at Balling Hall at the National Library of Technology (Technická 2710/6, 16080 Praha 6 - Dejvice). The Council meeting starts at 14.00 on June 23 and ends at lunch time on June 24.

\section{Delegates}

Delegates to the Council shall be elected for a period of four years. A delegate may be re-elected provided that consecutive service in the same capacity does not exceed eight years. Delegates will be elected by the following categories of members.

\section{(a) Full Members}

Full Members are national mathematical societies, which elect 1,2,3, or 4 delegates according to their membership class. The membership class is decided by Council, and societies are invited to apply for the new class 4 , which was introduced in the 2008 Council. However, the number of delegates for the 2018 Council is determined by the current membership class of the society.

Each society is responsible for the election of its delegates.

There is an online nomination form for delegates of full members. The deadline for nominations for delegates of full members is 15 April 2018.

\section{(b) Associate Members}

Delegates representing associate members shall be elected by a ballot organized by the Executive Committee from a list of candidates who have been nominated and seconded by associate members, and have agreed to serve. In October 2017, there were 2 associate members and, according to our statutes, these members may be represented by (up to) one delegate.

There is an online nomination form for delegates of associate members. The deadline for nominations for delegates of associate members is 15 March 2018.

\section{(c) Institutional Members}

Delegates representing institutional members shall be elected by a ballot organized by the Executive Committee from a list of candidates who have been nominated and seconded by institutional members, and have agreed to serve. In October 2017, there were 44 institutional members and, according to our statutes, these members may be represented by (up to) 4 delegates.

The delegate whose term includes 2018 is Klavdija Kutnar. The delegate who can be re-elected is Alberto Pinto.

There is an online nomination form for delegates of institutional members. The deadline for nominations for delegates of institutional members is 15 March 2018.

\section{(d) Individual Members}

Delegates representing individual members shall be elected by a ballot organized by the Executive Committee from a list of candidates who have been nominated and seconded, and have agreed to serve. These delegates must themselves be individual members of the European Mathematical Society.

In October 2017 there were 2816 individual members and, according to our statutes, these members may be 
represented by (up to) 28 delegates. However, this number may have increased by the time we call the election (if any) for individual members.

Here is a list of the current delegates of individual members whose terms include 2018:

Thierry Bouche

Jose Antonio Carrillo

Antonio Campillo

Piermarco Cannarsa

Carles Casacuberta i Vergés

Mireille Chaleyat-Maurel

Krzysztof Ciesielski

Pavel Exner

Paul C. Kettler

Bostjan Kuzman

Ari Laptev

Marta Mazzocco

Vicente Muñoz

José Francisco Rodrigues

Marie-Francoise Roy

Marta Sanz-Solé

Robin Wilson

Here is a list of the delegates of individual members who could be re-elected for the 2018 Council:

\section{Maria Esteban \\ Vincenzo Ferone \\ Luis Narvaáez Macarro \\ Jiří Rákosník}

There is an online nomination form for delegates of individual members. The deadline for nominations for delegates of individual members is 15 March 2018.

\section{Agenda}

The Executive Committee is responsible for preparing the matters to be discussed at Council meetings. Items for the agenda of this meeting of the Council should be sent as soon as possible, and no later than 15 April 2018, to the EMS Secretariat in Helsinki.

\section{Executive Committee}

The Council is responsible for electing the President, Vice-Presidents, Secretary, Treasurer and other members of the Executive Committee. The present membership of the Executive Committee, together with their individual terms of office, is as follows.
President: Pavel Exner (2015-2018)

Vice-Presidents: Volker Mehrmann (2017-2018)

Armen Sergeev (2017-2020)

Secretary: Sjoerd Verduyn Lunel (2015-2018)

Treasurer: Mats Gyllenberg (2015-2018)

Members: Nicola Fusco (2017-2020)

Stefan Jackowski (2017-2020)

Vicente Muñoz (2017-2020)

Beatrice Pelloni (2017-2020)

Betül Tanbay (2017-2020)

Members of the Executive Committee are elected for a period of four years. The President can only serve one term. Committee members may be re-elected, provided that consecutive service shall not exceed eight years.

The Council may, at its meeting, add to the nominations received and set up a Nominations Committee, disjoint from the Executive Committee, to consider all candidates. After hearing the report by the Chair of the Nominations Committee (if one has been set up), the Council will proceed to the elections to the Executive Committee posts.

All these arrangements are as required in the Statutes and By-Laws, which can be found here, together with the web page for the Council:

http://www.euro-math-soc.eu

The nomination form for full member delegates can be found here

https:/elomake.helsinki.fi/lomakkeet/81087/lomake. html

The nomination form for institutional, associate and individual member delegates can be found here

https:/elomake.helsinki.fi/lomakkeet/81089/lomake. html

Secretary: Sjoerd Verduyn Lunel (s.m.verduynlunel@uu.nl)

Secretariat: ems-office@helsinki.fi 